\title{
Characterization of VIM and IMP Metallobetalactamases (MBL) in Pseudomonas aeruginosa Isolated in a Tertiary Care Hospital
}

\author{
R. Mahesh Reddy*, Satish Kumar and Mahadevan Kumar \\ Department of Microbiology, Armed Forces Medical College, \\ Pune-411048, Maharashtra, India \\ *Corresponding author
}

\begin{tabular}{|c|c|}
\hline & A B S T R A C T \\
\hline $\begin{array}{l}\text { Ke y w or d s } \\
\text { Carbapenem } \\
\text { resistance, } \\
\text { Pseudomonas } \\
\text { aeruginosa, } \\
\text { Metallo- } \\
\text { betalactamases } \\
\text { (MBL), MBL } \\
\text { genes. }\end{array}$ & $\begin{array}{l}\text { Resistance to carbapenems are because of various mechanisms like mutations in the outer } \\
\text { membrane proteins like Opr D causing decreased permeability of the drugs, the } \\
\text { carbapenem hydrolyzing enzymes-carbapenemases and the efflux mechanisms. } \\
\text { Carbapenem resistance was studied in } 140 \text { non-repeat clinical isolates of Pseudomonas } \\
\text { aeruginosa in a tertiary care hospital. Imipenem resistance was detected using Kirby } \\
\text { Bauer's standard disc diffusion method. MIC for Imipenem was detected in all resistant } \\
\text { isolates using E-test strips. Production of Metallo-betalactamases (MBL) was detected } \\
\text { using phenotypic MBL E-test method. MBL producing genes were tested in Pseudomonas } \\
\text { using conventional PCR for IMP, VIM-type genes. Out of } 140 \text { isolates, } 68 \text { (48.5 \%) }\end{array}$ \\
\hline Article Info & $32 \mu \mathrm{g} / \mathrm{ml}$. MBL E-test, showed $54(79.4 \%)$ as positive for MBL. The PCR analysis of the \\
\hline $\begin{array}{l}\text { Accepted: } \\
\text { 22 February } 2017 \\
\text { Available Online: } \\
10 \text { March } 2017\end{array}$ & $\begin{array}{l}54 \text { isolates which were detected to have MBL showed VIM type (43\%), IMP-1 (12\%), } \\
\text { IMP-2 }(2 \%) \text { like genes. There is high level of prevalence of imipenem resistance in the } \\
\text { Pseudomonas aeruginosa strains isolated. The carbapenem resistance in Pseudomonas } \\
\text { aeruginosa in our hospital setting is mainly because of MBL gene that is of VIM type. }\end{array}$ \\
\hline
\end{tabular}

\section{Introduction}

The early eighties saw the introduction of a new group of antibiotics known as the carbapenems, which exhibited broader spectrum of activity as compared to cephalosporins. These group of antibiotics were active against Gram negative bacilli including non-fermenters like Pseudomonas producing extended spectrum betalactamases (ESBLs) and AmpC betalactamases (Deshpande et al., 2004; Gladstone et al., 2005). However, reports of resistance to these antibiotics amongst non-fermenting Gram negative bacteria (NFGNB) particularly
Pseudomonas aeruginosa have been published in the last decade. The strains of carbapenem resistant Pseudomonas aeruginosa can cause serious outbreaks in immunocompromised and hospitalized patients especially those admitted to intensive care and acute care units (Gowda and Marie, 2014; Maltezou et al., 2013).

Resistance to carbapenems are because of various mechanisms such as mutations in the outer membrane proteins like Opr D causing decreased permeability of the drugs, the 
carbapenem hydrolyzing enzymescarbapenemases, and efflux mechanisms. Out of these, the resistant mechanism because of Carbapenem hydrolyzing enzymes is commonest and has gained much importance because of their horizontal spread to other Gram negative bacteria by plasmid mediated transfer (Maltezou et al., 2013; Walsh et al., 2005). Of the Carbapenemases, the Metallobetalactamases (MBLs) are the commonest. Their activity is dependent on divalent cations like zinc or cadmium, so they can be inhibited by metal chelators such as ethylene diamine tetra acetic acid (EDTA), 2- mercapto propionic acid.

MBLs are broad-spectrum enzymes that hydrolyse most beta-lactam antibiotics, except monobactams and are not inhibited by conventional beta--lactamase inhibitors such as clavulanic acid or sulbactam. MBLs fall under group B of the Ambler classification. This group is further sub- divided into three subclasses: B-I, B-II, and B-III. The commonly occurring subclass is B-I and it comprises IMP (Imipenemase), VIM(Verona integron encoded metallo-beta-lactamase), GIM (Germany Imipenemase), and SPM (Sao Paulo metallo-beta-lactamase), FIM (Florence Imipenemase) types based on the their molecular structure (Walsh et al., 2005).

The newest type detected recently in India is New Delhi metallo beta lactamase-1 (NDM1) and the prevalence of NDM-1 carbapenemase in Pseudomonas in India is low (Khajuria et al.. 2013; Shanthi et al., 2014). Of all the MBL types the most widely prevalent types are the IMP and VIM like MBL genes. The present study was done to detect the Carbapenem resistance due to Ambler class B carbapenemases which are known as MBLs by a phenotypic method along with the present gold standard (molecular detection of incriminating genes) for detection of two of the metallo-betalactamases, VIM and IMP as they are of most predominant type.

\section{Materials and Methods}

The study was carried out in the department of microbiology, of a tertiary care hospital for one year. A total of 140 consecutive, nonrepeat isolates of Pseudomonas aeruginosa were collected from various clinical samples like tracheal aspirate, bronchoalveolar lavage, sputum, blood etc. All the isolates were identified based on colony morphology, biochemical characteristics, and oxidative fermentation tests as per standard identification methods. Pseudomonas aeruginosa ATCC27853 was used as a control.

Antibiotic susceptibility testing for Imipenem and other antimicrobial agents was carried out using Kirby Bauer's standard disc diffusion method as per CLSI (Clinical and Laboratory Standards Institute, 2012) standard tables. For the antimicrobial susceptibility testing the antibiotic disks (HiMedia, Mumbai, India) used were imipenem $(10 \mu \mathrm{g})$, ciprofloxacin (5 $\mu \mathrm{g})$, norfloxacin $(10 \mu \mathrm{g})$ ceftazidime $(30 \mu \mathrm{g})$, cefipime $(30 \mu \mathrm{g})$, aztreonam $(30 \mu \mathrm{g})$, amikacin $(30 \mu \mathrm{g})$, ticarcillin $(75 \mu \mathrm{g})$, and piperacillin $(100 \mu \mathrm{g})$, piperacillin-tazobactum $(100 / 10 \mu \mathrm{g})$, colistin $(10 \mu \mathrm{g})$, polymyxin B (300 U). Pseudomonas aeruginosa ATCC27853 was used as control.

Screening for Carbapenem group susceptibility was performed using Imipenem (IPM) disc of $10 \mu \mathrm{g}$. Isolates were considered Imipenem resistant if the inhibitory zone diameters were as per CLSI guidelines (2012).Minimum Inhibitory Concentrations (MIC) for Imipenem was determined for all the resistant isolates using Epsilometer (Etest) strips (Biomerieux, France). According to CLSI guidelines the breakpoint MIC was taken as $\geq 8 \mu \mathrm{g} / \mathrm{mL}$, Sensitivity to Imipenem was taken as $\leq 2 \mu \mathrm{g} / \mathrm{ml}$. 
Screening for MBL production amongst the imipenem resistant isolates was carried out using a phenotypic MBL E-test method (Behera et al., 2008; Walsh et al., 2002; Yong et al., 2002). The MBL E Test strip contains aseven dilution range of IPM (4 to 256 $\mu \mathrm{g} / \mathrm{mL}$ ) on one end and IPM (1 to $64 \mu \mathrm{g} / \mathrm{mL}$ ) in combination with fixed concentration of EDTA on the other end.

The MBL E-test was performed based on manufacturer's instructions. The strain was considered as an MBL producer if the MIC ratio of IPM/IPI (Imipenem and Imipenem along with an Inhibitor-EDTA) $\geq 8$ or $\geq 3 \log$ dilutions. Formation of a phantom zone or deformation of the ellipse was also interpreted as positive for MBL irrespective of the IPM/IPI ratio. MBL Negative control used was Pseudomonas aeruginosa ATCC 27853 with MIC of IPM $\leq 4 \mu \mathrm{g} / \mathrm{ml}$ and that of IPI 1$4 \mu \mathrm{g} / \mathrm{ml}$.

All Carbapenem resistant Pseudomonas isolates, were screened for presence of MBL producing genes IMP, VIM using conventional PCR technique (Marchiaro et $a l .$, 2005). Nucleic acid extraction was done from the resistant isolates using QIAmp DNA extraction Kit (Qiagen, USA) according to the manufacturer's protocol. The reaction was performed in a volume of $25 \square 1$ with $18 \square \square 1$ of 2x Mastermix (Thermo Fisher Scientific, India), $2 \square 1$ of the primers (SigmaAldrich, India) and $5 \square \square 1$ of template DNA. Primer sequences, Cycling parameters and the expected amplicon size are summarized in table 1.

\section{Results and Discussion}

Sixty eight $(48.5 \%)$ of the 140 isolates were found to be Imipenem resistant by Kirby Bauer's standard disc diffusion method. The Imipenem resistant isolates were mainly isolated from ICU and acute care wards (70 $\%$ ) and the sample distribution is as given in figure 1 .

The antibiogram of the Imipenem resistant isolates is depicted in figure 2. Of the 68 total resistant isolates of Pseudomonas aeruginosa, $100 \%$ were resistant to piperacillin, ceftazidime and cefepime, $31(45.5 \%)$ to piperacillin/ tazobactam, $45(66 \%)$ to amikacin, 26 (38\%) to Aztreonam 64 (94\%) to ciprofloxacin, but all (100\%) were sensitive to polymyxin B and colistin. Majority 39 of $68(58 \%)$ of the Imipenem resistant isolates exhibited an $\mathrm{MIC}$ of $\geq$ $32 \mu \mathrm{g} / \mathrm{ml}$ by E-test, 21 of 68 exhibited MIC of $\geq 24 \mu \mathrm{g} / \mathrm{ml}$ and 8 of 68 exhibited MIC of $\geq 16$ $\mu \mathrm{g} / \mathrm{ml}$.

MBL E test that was used to screen for the production of MBL showed 54 (79.4\%) of 68 imipenem resistant isolates of Pseudomonas aeruginosa positive for MBL production (Fig. 3 ). The PCR analysis of the 54 isolates which were detected to have MBL showed VIM type (43\%) (Fig. 4), IMP-1 (12\%), IMP-2 (2\%) like genes.

Table.1 Summary of the primers, cycling conditions and amplicon size

\begin{tabular}{|c|c|c|c|c|c|}
\hline \multirow{2}{*}{ GENE } & \multirow{2}{*}{$\begin{array}{c}\text { PRIMER SEQUENCE } \\
\text { Sequence }\left(5^{\prime} \rightarrow 3^{\prime}\right)\end{array}$} & \multirow{2}{*}{ AMPLICON SIZE (bp) } & \multicolumn{3}{|c|}{ CYCLING CONDITIONS (30 cycles) } \\
\hline & & & Denaturation & Annealing & Extension \\
\hline \multirow{2}{*}{ IMP 1} & (F): GAGCAAGTTATTTGTATTCT & \multirow{2}{*}{630} & \multirow{2}{*}{ Dentatur ation } & \multirow{2}{*}{$49^{\circ} \mathrm{C}$} & \multirow{2}{*}{$72^{\circ} \mathrm{C}$} \\
\hline & (R): ACCAGTTTTGCCTTACTATA & & & & \\
\hline \multirow{2}{*}{ IMP 2} & (F): TGTTTTATGTGTATGCTTCC & \multirow{2}{*}{708} & \multirow{2}{*}{$95^{\circ} \mathrm{C}$} & \multirow{2}{*}{$54^{\circ} \mathrm{C}$} & \multirow{2}{*}{${ }^{72} 2^{\circ} \mathrm{C}$} \\
\hline & (R): AGTTACTTGGCTGTGATGGT & & & & \\
\hline VIM & $\begin{array}{l}\text { (F): ATTGGTCTATTTGACCGCGT } \\
\text { (R): CTACTCAACGACTGAGCGT }\end{array}$ & 780 & $95^{\circ} \mathrm{C}$ & $58^{\circ} \mathrm{C}$ & $7^{\circ} \mathrm{C}$ \\
\hline
\end{tabular}


Fig.1 Antibiogram of the imipenem resistant isolates of Pseudomonas

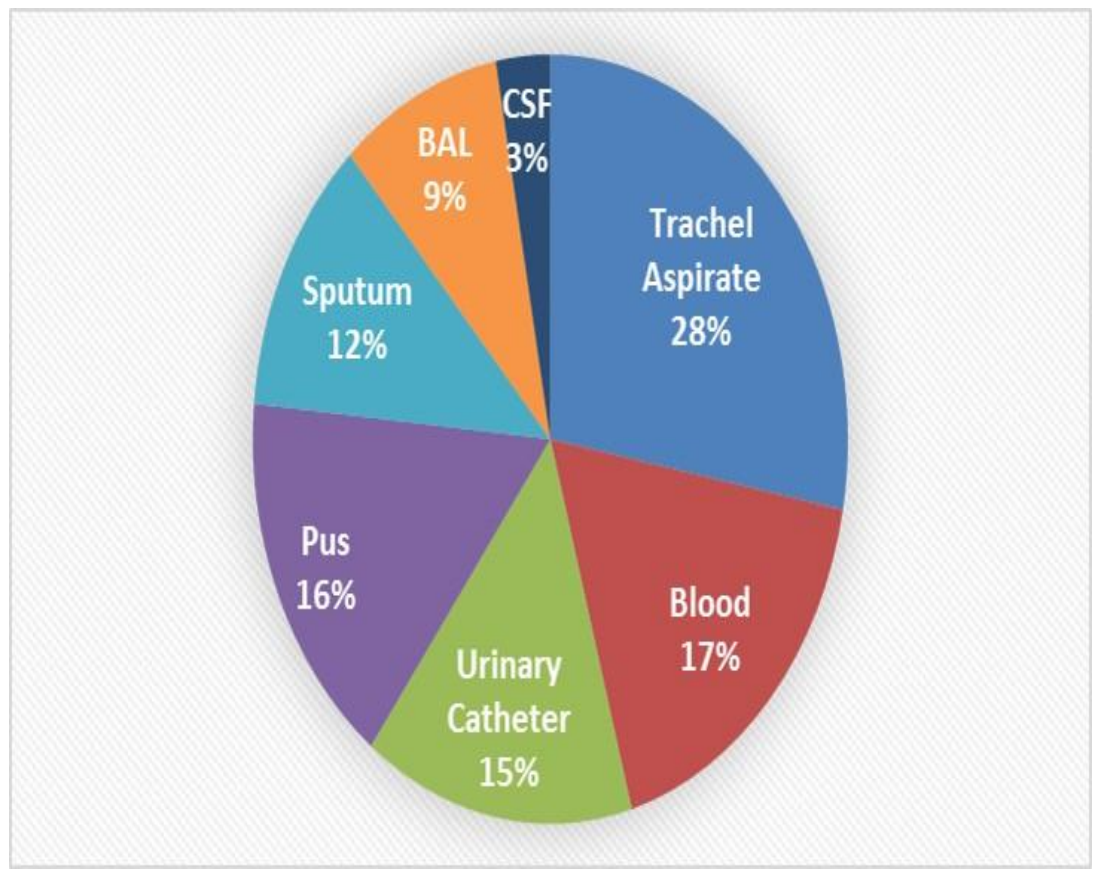

Fig.2 Antibiogram of the Imipenem resistant isolates of Pseudomonas

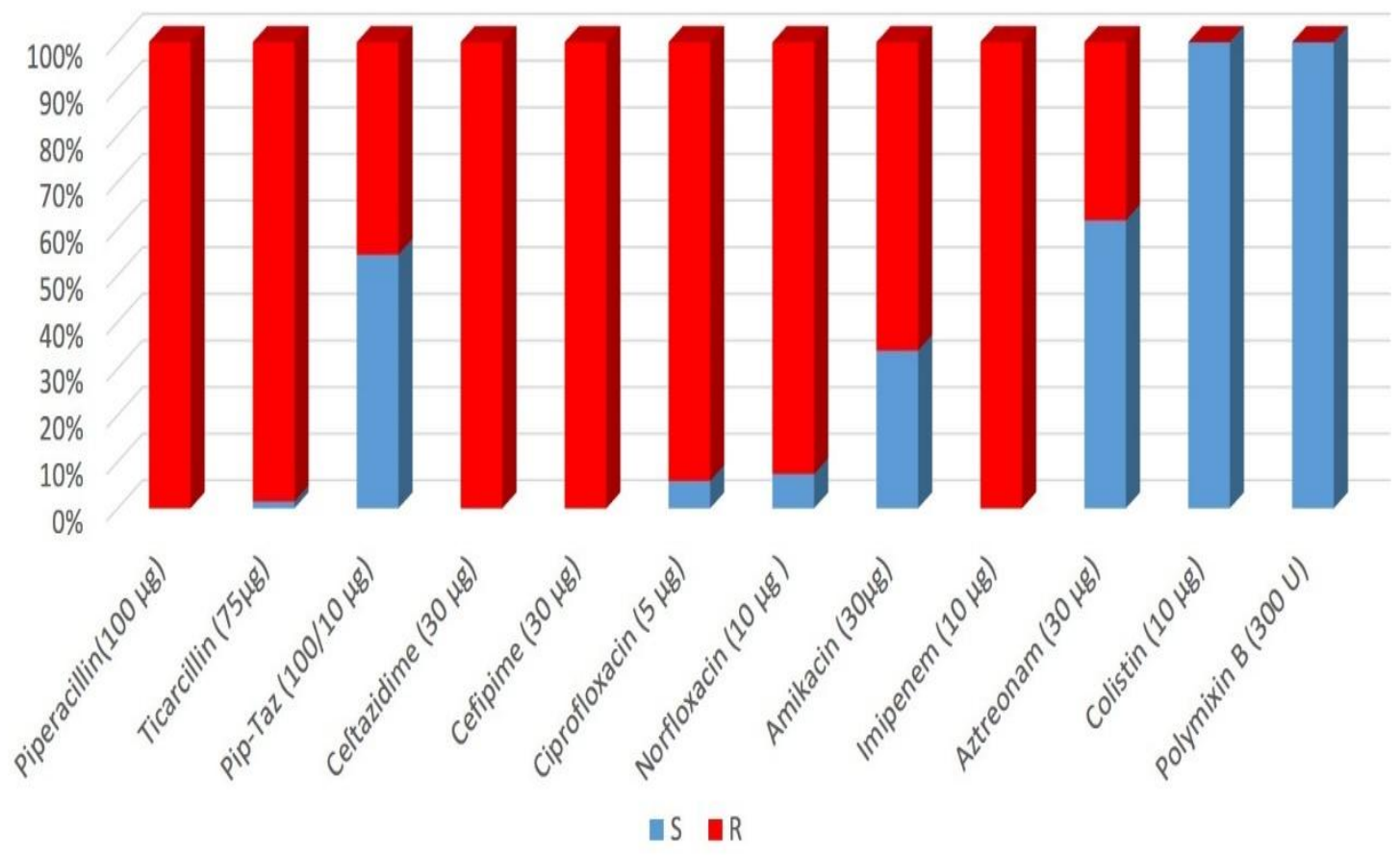


Fig.3 Panel A and B: Detection of Metallo-beta-lactamase (MBL) by E test. Panel C: Imipenem sensitive strain. Panel D: Imipenem resistant but non MBL producing Pseudomonas spp.
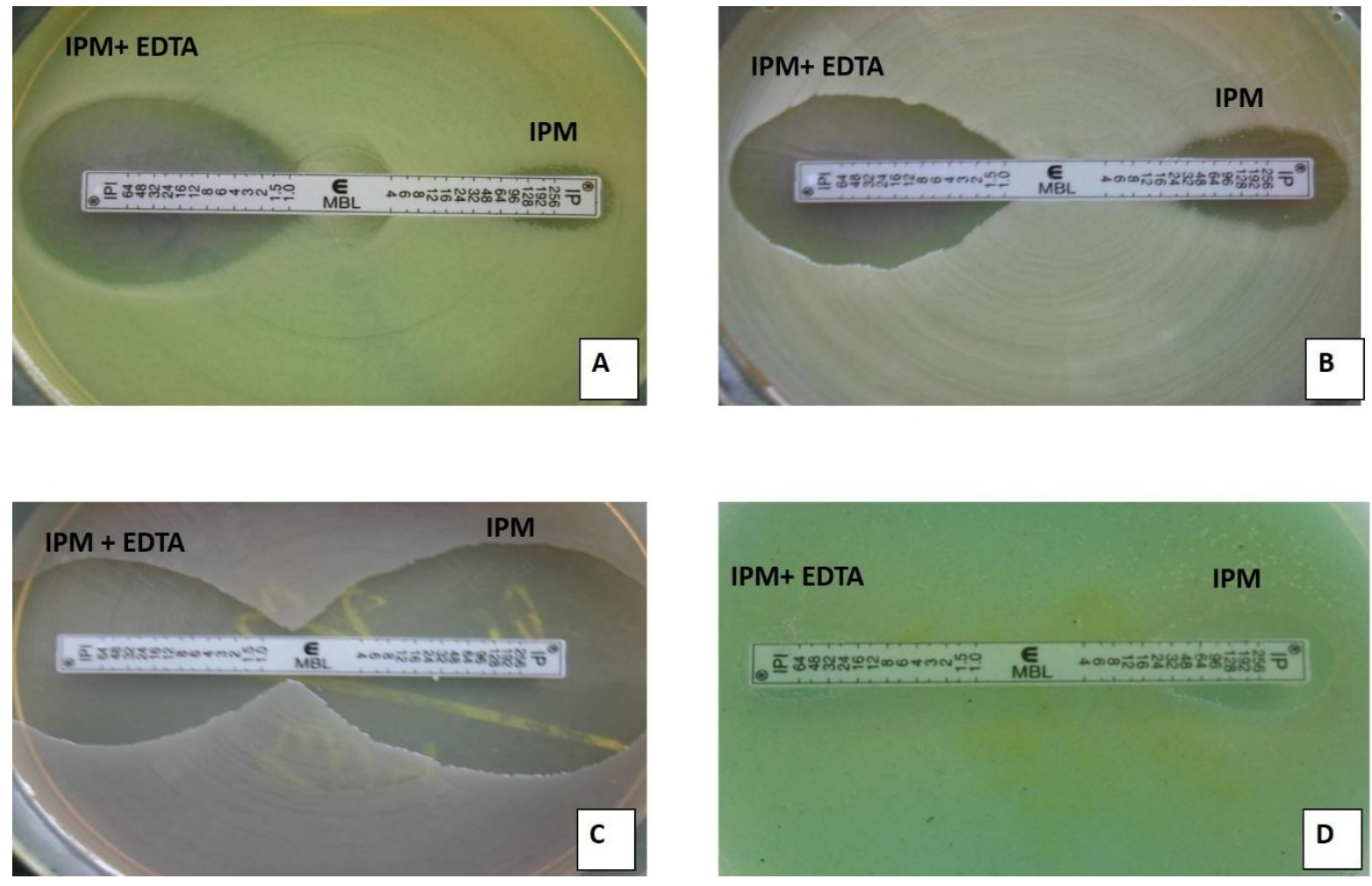

Fig.4 Agarose gel electrophoresis for detection of VIM gene. NC - Negative control, 23-28 samples, MWM - 100bp DNA ladder. Samples 24 and 28 show band for VIM type gene at $780 \mathrm{bp}$

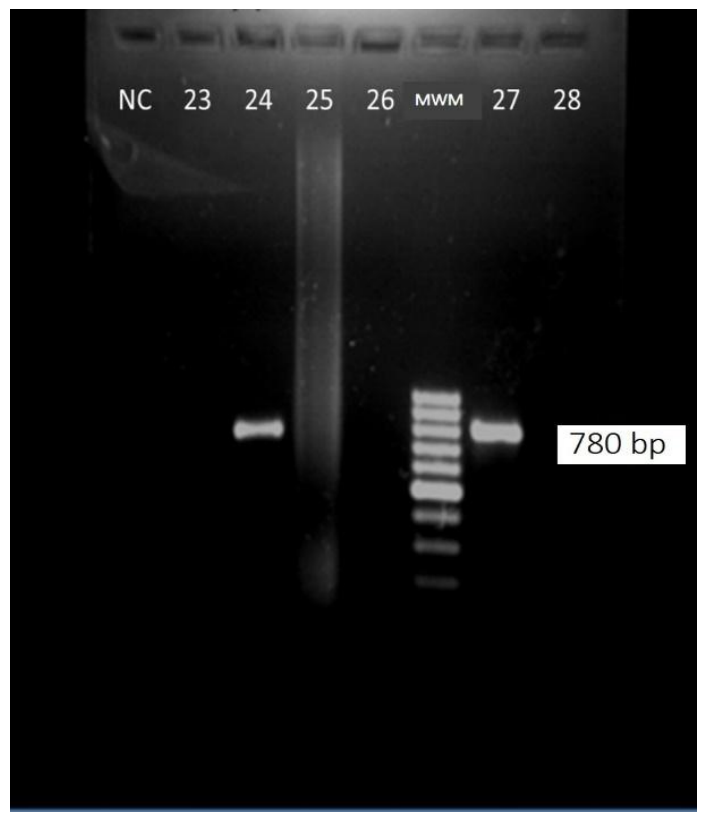


There is high level of prevalence of Imipenem resistance $(48.5 \%)$ in the strains of Pseudomonas aeruginosa isolated from our Hospital. The Imipenem resistant strains of Pseudomonas were predominantly isolated from blood, pus, urine and tracheal aspirate. Majority of resistant strains isolated were mainly from ICU $(45 \%)$ and Acute Medical Care unit (25\%). The antibiogram demonstrates that all these isolates are fully resistant to piperacillin, majority to ciprofloxacin and third/fourth generation cephalosporins like ceftazidime and cefipime. These strains were sensitive to only polymyxin B (100\%), colistin (100\%) and aztreonam (94\%). This multi drug resistance amongst the Imipenem resistant isolates severely limits our therapeutic options in treating these infections. The MBL positive strains are, at present, sensitive to polymyxin B and polymyxin $\mathrm{E}$ (Colistin). Colistin may be combined with tigecycline as combination therapy for better results (Betts et al., 2014; Datta and Wattal, 2010). The strains isolated from ICU showed same antibiogram profile indicating the possibility of origin from the same clone, but it needs to be confirmed by DNA sequencing. The infection control measures have been adequately instituted in the hospital to further contain the spread of this strain.

The PCR analysis for the MBL genes showed predominantly VIM type (43\%) genes and IMP (14\%) type in our setting, similar prevalence was seen ranging from $18 \%$ to $56 \%$ for VIM and $22 \%$ to $48 \%$ for IMP type in other studies (Doosti et al., 2013; Irfan et al., 2008; Kim et al., 2012; Lee et al., 2002). In another study, there was prevalence of $17.8 \%$ VIM type MBLs in the Citrobacter spp (Praharaj et al., 2016). Reports of these kinds of MBL genes are presently less in number as far as India is concerned. The presence of MBL genes in only $57 \%$ of the resistant strains of Pseudomonas in this study indicates the possibility of multiple mechanisms responsible for resistance to Imipenem like mutations in the outer membrane proteins Opr D, the efflux mechanisms such as Mex A and Mex-B with Opr M which need to be tested and confirmed. In conclusion, continuous surveillance and strict infection control measures are warranted to control carbapenem resistance in all health care settings.

\section{Acknowledgement}

The authors are grateful to all the faculty and laboratory staff of Dept of Microbiology, for their support.

Conflict of Interests: None to declare.

\section{References}

Behera, B., P. Mathur, A. Das, A. Kapil, and V. Sharma. 2008. "An Evaluation of Four Different Phenotypic Techniques for Detection of Metallo-Beta-Lactamase Producing Pseudomonas Aeruginosa." Indian J. Med. Microbiol., 26(3): 233-37.

Betts, Jonathan, W., Lynette, M., Phee, Michael Hornsey, Neil Woodford, and David, W., Wareham. 2014. "In Vitro and In Vivo Activities of Tigecycline-Colistin Combination Therapies against Carbapenem- Resistant Enterobacteriaceae." Antimicrobial Agents and Chemother., 58(6): 3541-46.

Datta, Sanghamitra and Chand Wattal. 2010. "Carbapenemase Producing Gram Negative Bacteria in Tertiary Health Care Setting: Therapeutic Challenges." 23(1): 17-20.

Deshpande, Lalitagauri, M., Thomas, R. Fritsche, and Ronald, N., Jones. 2004. "Molecular Epidemiology of Selected MultidrugResistant Bacteria: A Global Report from the SENTRY Antimicrobial Surveillance Program." Diag. Microbiol. Infect. Dis., 49(4): 231-36.

Doosti, Masoumeh, Ali Ramazani, and Maryam Garshasbi. 2013. "Identification and Characterization of Metallo- $\beta$-Lactamases Producing Pseudomonas Aeruginosa Clinical Isolates in University Hospital from Zanjan Province, Iran." Iranian Biomed. J., 17(3): 129-33.

Gladstone, P., P. Rajendran, and K.N. Brahmadathan. 2005. "Incidence of 
Carbapenem Resistant Nonfermenting Gram Negative Bacilli from Patients with Respiratory Infections in the Intensive Care Units." Indian J. Med. Microbiol., 23(3): 189-91.

Gowda, Lakshmana K. and Mohammed Ali M. Marie. 2014. "Epidemiology of Carbapenem-Resistant and Noncarbapenem-Resistant

Enterobacteriaceae and Issues Related to Susceptibility Testing, Treatment Options, and Clinical Outcome." Reviews in Med. Microbiol., 25(3).

Irfan, S., A. Zafar, D. Guhar, T. Ahsan, and R. Hasan. 2008. "Metallo-Beta-LactamaseProducing Clinical Isolates of Acinetobacter Species and Pseudomonas Aeruginosa from Intensive Care Unit Patients of a Tertiary Care Hospital." Indian J. Med. Microbiol., 26(3): 243-45.

Khajuria, Atul, Ashok Kumar Praharaj, Mahadevan Kumar, and Naveen Grover. 2013. "Emergence of NDM - 1 in the Clinical Isolates of Pseudomonas Aeruginosa in India." J. Clin. Diag. Res. JCDR, 7(7): 1328-31.

Kim, Min Ji, et al. 2012. "Genotypic Investigation of Multidrug-Resistant Pseudomonas Aeruginosa from Clinical Isolates in Korea, 2010." Korean J. Microbiol., 48(4): 240 45.

Lee, Kyungwon, et al. 2002. "bla(VIM-2) Cassette-Containing Novel Integrons in Metallo- $\beta$-Lactamase-Producing

Pseudomonas Aeruginosa and Pseudomonas Putida Isolates Disseminated in a Korean Hospital." Antimicrobial Agents and Chemother., 46(4): 1053-58. Maltezou, Helena, C., et al. 2013. "Infections
Caused by Carbapenem-Resistant GramNegative Pathogens in Hospitalized Children." The Pediatric Infect. Dis. J., 32(4): e151-4.

Marchiaro, Patricia, et al. 2005. "Sensitive EDTA-Based Microbiological Assays for Detection of Metallo-\{beta\}-Lactamases in Nonfermentative Gram-Negative Bacteria." J. Clin. Microbiol., 43(11): 5648-52.

Praharaj, Ashok Kumar, Atul Khajuria, Mahadevan Kumar, and Naveen Grover. 2016. "Phenotypic Detection and Molecular Characterization of Beta-Lactamase Genes among Citrobacter Species in a Tertiary Care Hospital." Avicenna J. Med., 6(1): 1727.

Shanthi, Mariappan, Uma Sekar, Arunagiri Kamalanathan, and Balaraman Sekar. 2014. "Detection of New Delhi Metallo Beta Lactamase-1 (NDM-1) Carbapenemase in Pseudomonas Aeruginosa in a Single Centre in Southern India." The Indian J. Med. Res., 140(4): 546-50.

Walsh, Timothy, R., Anne Bolmstrom, Anette Qwarnstrom, and Ana Gales. 2002. "Evaluation of a New Etest for Detecting Metallo-Beta-Lactamases in Routine Clinical Testing." J. Clin. Microbiol., 40(8): 2755-59.

Walsh, Timothy, R., Mark, A., Toleman, Laurent Poirel, and Patrice Nordmann. 2005. "Metallo-Beta-Lactamases: The Quiet before the Storm?" Clin. Microbiol. Rev., 18(2): 306-25.

Yong, Dongeun, et al. 2002. "Imipenem-EDTA Disk Method for Differentiation of Metallo$\beta$-Lactamase-Producing Clinical Isolates of Pseudomonas Spp. and Acinetobacter Spp." J. Clin. Microbiol., 40(10): 3798-3801.

\section{How to cite this article:}

Mahesh Reddy, R., Satish Kumar and Mahadevan Kumar. 2017. Characterization of VIM and IMP Metallobetalactamases (MBL) in Pseudomonas aeruginosa Isolated in a Tertiary Care Hospital. Int.J.Curr.Microbiol.App.Sci. 6(3): 1461-1467. doi: https://doi.org/10.20546/ijcmas.2017.603.167 